\title{
The search for underlying principles of health impact assessment: progress and prospects Comment on "Investigating underlying principles to guide health impact assessment"
}

\author{
Mirko S. Winkler ${ }^{1,2, *}$, Jürg Utzinger ${ }^{1,2}$
}

\section{Abstract}

Health Impact Assessment (HIA) is a relatively young field of endeavour, and hence, future progress will depend on the planning, implementation and rigorous evaluation of additional HIAs of projects, programmes and policies the world over. In the June 2014 issue of the International Journal of Health Policy and Management, Fakhri and colleagues investigated underlying principles of HIA through a comprehensive review of the literature and expert consultation. With an emphasis on the Islamic Republic of Iran, the authors identified multiple issues that are relevant for guiding HIA practice. At the same time, the study unravelled current shortcomings in the understanding and definition of HIA principles and best practice at national, regional, and global levels. In this commentary we scrutinise the research presented, highlight strengths and limitations, and discuss the findings in the context of other recent attempts to guide HIA.

Keywords: Health Impact Assessment (HIA), Guidelines, Islamic Republic of Iran

Copyright: @ 2014 by Kerman University of Medical Sciences

Citation: Winkler MS, Utzinger J. The search for underlying principles of health impact assessment: progress and prospects; Comment on "Investigating underlying principles to guide health impact assessment". Int J Health Policy Manag 2014; 3: 107-109. doi: 10.15171/ijhpm.2014.69
Article History:

Received: 9 July 2014

Accepted: 25 July 2014 ePublished: 26 July 2014

*Correspondence to:

Mirko S. Winkler

Email: mirko.winkler@unibas.ch
$\mathrm{H}$ ealth Impact Assessment (HIA) is an interdisciplinary, multi-sectorial approach that takes into account social, environmental, economic and political factors, as it is widely acknowledged that the interplay of these factors collectively determine health, equity and wellbeing (1). Over the past 20 years, HIA practice has developed in many parts of the world, resulting in considerable diversity in HIA applications for projects, programmes, and policies $(2,3)$. For example, in a recent literature review, Hebert and colleagues (4) identified 45 local, national and international HIA guidelines that have been published in the English language. Whilst such evidence is proof of growing HIA practice, the diversity in underlying frameworks and principles, methodological approaches and technical terminology poses challenges when it comes to the development and application of HIA guidelines that are readily adapted to a specific context, need and setting. In the June 2014 issue of the International Journal of Health Policy and Management, Fakhri and colleagues (5) investigated underlying principles of HIA. Their goal was to systematise and guide HIA practice, placing particular emphasis on the Islamic Republic of Iran. The authors pursued a comprehensive literature review, in order to identify criteria for comparing HIA guides and characteristics. Identified HIA characteristics were categorised and translated into underlying principles that can guide the HIA process. The last step involved consultation with five local experts thus promoting participation in the decision-making process; an approach phrased nominal group technique (6).

The key findings can be summarised as follows. First, more than 60 criteria for comparing HIA guides were assembled from just six articles that critically investigated differences and commonalities of HIA guides. Second, no uniform criteria across the six identified papers were detected. Third, a total of 122 HIA characteristics were identified, and these were grouped into 14 categories of underlying principles of the HIA process. As expected, many of these categories are consistent with underlying principles of HIA described in previous research and guidance documents $(1,7,8)$. Fourth, the authors put forward a set of additional characteristics that should be considered for the development of a conceptual framework for HIA in the Islamic Republic of Iran. Fakhri and colleagues conclude that it will be eminently feasible to develop a universal HIA guide that covers all principles described thus far in the peer-reviewed literature.

We feel that the research presented by Fakhri et al. makes a valuable contribution to HIA. Indeed, HIA is quite a young field of endeavour that critically depends on many more HIAs being conducted in different parts of the world, including underlying principles and how HIA can be institutionalised. That said, another aspect worth highlighting is that Fakhri succeeded in publishing the key findings of his $\mathrm{PhD}$ thesis in the peer-reviewed literature. This is a great achievement and bodes well with HIA capacity building and practice strengthening in the Islamic Republic of Iran. Yet, it is to be hoped that-for subsequent appraisals-criteria for systematically reviewing the literature will be applied more stringently. For example, the search strategy, details about inclusion and exclusion criteria, including study flow

Full list of authors' affiliations is available at the end of the article. 
diagram, grading of quality of the identified studies, potential for publication bias, etc. are essential elements, without which it will be difficult to the reader to fully reproduce the research performed. Moreover, the fact that the literature review was restricted to the period from 1 January 1995 to 30 April 2012 is of concern, as the most recent data (from May 2012 onwards) obviously will have been missed. HIA is a rapidly evolving field, and hence, it is conceivable that the most recent guides and principles were not included. Rigorous adherence to international guidelines on systematic reviews, such as those provided by the Cochrane Collaboration for clinical research (http://www.cochrane.org) and the 'Preferred Reporting Items for Systematic Reviews and Meta-Analyses' (PRISMA) guidelines for systematic reviews (9) would have been useful to follow.

Taken together, Fakhri et al's observations align with a set of papers that have been published in recent years, all of which-directly or indirectly-stress the importance of coming to a shared and timely understanding of HIA principles and practice. For instance, Krieger and colleagues (10) challenged whether the HIA framework presented in the Gothenburg consensus paper in 1999 is still fit for purpose of current global HIA practice. Of note, the Gothenburg HIA framework emphasised four core values: democracy, equity, sustainable development, and ethical use of evidence. Equity considerations were incorporated into the Gothenburgdriven HIA model by embracing the work of the World Health Organization's Commission on Social Determinants of Health, which ultimately resulted in an HIA methodology that was mainly based on the social determinants of health model. Krieger's commentary published in the Lancet triggered a call by Vohra and colleagues (11) to develop a post-Gothenburg international HIA consensus that further moves ahead the HIA field. Harris-Roxas and Harris (2) established a typology of HIA practice, presenting different forms of HIA that have evolved, which serve different purposes but are not necessarily in competition. The comparison of a large number of HIA guidelines conducted by Hebert and colleagues (4) identified many similar, but not identical processes for conducting HIA. Finally, Schuchter and colleagues (12) studied whether HIA practice in the United States of America has followed standards. In that paper a diverse practice of HIA becomes transparent that varies considerably relative to current practice standards.

Apparently, there is consensus among many HIA practitioners that almost 20 years after Scott-Samuel's seminal paper entitled 'HIA an idea whose time has come' (13), the time for developing an updated international consensus on HIA is ripe. Of note, an international consensus only defines governing values and standards that apply to the use of HIA in order to ensure they are relevant to the current diverse range of HIA practice (14). Hence, international consensus as discussed in our commentary is not a substitute for HIA guidelines that are readily adapted to given contexts and needs. The endeavour of developing an updated international consensus on HIA would offer many opportunities. First, to define a common basis for HIA practice after two decades of diversification will consolidate, perhaps unify and certainly strengthen the
HIA field. Second, practitioners from all major regions of the world - until the late 2000s, HIA practice has primarily been defined by practitioners from industrialized countries (15) must have a say in the definition of underlying principles for guiding HIA practice. Third, HIA practitioners need guidance on methodological frameworks for addressing major challenges of the $21^{\text {st }}$ century, such as rapid urbanization, vast expansion of extractive industries in developing countries, global climate change and green economy strategies $(16,17)$. Fourth, a common HIA terminology (e.g. type, level, and focus of HIA) and a catalogue of potential processes (e.g. steps, tools, and methods) will help practitioners to better communicate among them and with other stakeholders (4). Fifth, with the definition of a set of HIA performance indicators, evaluation of HIA practice will be strengthened across different continents and fields of application (18). Finally, an international consensus on HIA will help regions and countries with different social, economic, environmental, and health systems contexts to develop their own HIA guidelines and regulatory frameworks, as shown by the given example by Fakhri and colleagues (5). However, the challenge for developing an international consensus on HIA will be to provide clear guidance while not inhibiting creative innovation for HIA applications. This is crucial since HIA guides that are readily adapted to specific needs (e.g. HIA guidelines of the International Finance Institutions) and different contexts are an important characteristic of HIA practice $(4,14)$. This also includes tools and methods that are tailored to local contexts and applications (19).

It is hoped that the calls for developing a universal HIA guide, built on HIA principles that are embraced by key stakeholders, will be taken up by global health authorities and the HIA community in the near future. Otherwise the HIA approach may face an identity crisis, with the ultimate risk to weaken itself due to a missing common basis and too much diversification. The research presented by Fakhri and colleagues nicely illustrates that there is a next generation of HIA academics and practitioners arising, which are eager to take up the challenge.

Ethical issues Not applicable.

Competing interests

Authors declare that they have no competing interests.

Authors' contributions

MSW and JU contributed equally to the drafting and revising of the manuscript and have read and approved the final version.

Authors' affiliations

${ }^{1}$ Department of Epidemiology and Public Health, Swiss Tropical and Public Health Institute, Basel, Switzerland. ' $U$ niversity of Basel, Petersplatz, Basel, Switzerland.

\section{References}

1. Kemm J. Health impact assessment: past achievement, current understanding, and future progress. Oxford: Oxford University Press; 2012. doi: 10.1093/acprof:oso/9780199656011.001.0001

2. Harris-Roxas $B$, Harris E. Differing forms, differing purposes: a typology of health impact assessment. Environ Impact Assess Rev 2011; 31: 396-403. doi: 10.1016/j.eiar.2010.03.003 
3. Harris P, Sainsbury P, Kemp L. The fit between health impact assessment and public policy: practice meets theory. Soc Sci Med 2014; 108: 46-53.

4. Hebert KA, Wendel AM, Kennedy SK, Dannenberg AL. Health impact assessment: a comparison of 45 local, national, and international guidelines. Environ Impact Assess Rev 2012; 34: 74-82. doi: 10.1016/j.eiar.2012.01.003

5. Fakhri A, Maleki M, Gohari M, Harris P. Investigating underlying principles to guide health impact assessment. Int J Health Policy Manag 2014; 3: 17-22. doi: 10.15171/ijhpm.2014.50

6. Delbecq AL, Van de Ven AH, Gustafson DH. Group techniques for program planning: a guide to nominal group and Delphi processes. Glenview, Illinois: Scott Foresman and Company; 1975.

7. Douglas MJ, Conway L, Gorman D, Gavin S, Hanlon P. Developing principles for health impact assessment. J Public Health Med 2001; 23: 148-54. doi: 10.1093/pubmed/23.2.148

8. Quigley RL, den Broeder P, Furu P, Bond B, Cave B, Bos R. Health impact assessment international best practice principles. Fargo: International Association for Impact Assessment; 2006.

9. Moher D, Liberati A, Tetzlaff J, Altman DG. Preferred reporting items for systematic reviews and meta-analyses: the PRISMA statement. PLoS Med 2009; 6: 6. doi: 10.1371/journal. pmed. 1000097

10. Krieger GR, Utzinger J, Winkler MS, Divall MJ, Phillips SD, Balge MZ, et al. Barbarians at the gate: storming the Gothenburg consensus. Lancet 2010; 375: 2129-31. doi: 10.1016/s01406736(10)60591-0

11. Vohra S, Cave B, Viliani F, Harris-Roxas BF, Bhatia R. New international consensus on health impact assessment. Lancet
2010; 376: 1464-5. doi: 10.1016/s0140-6736(10)61991-5

12. Schuchter J, Bhatia R, Corburn J, Seto E. Health impact assessment in the United States: has practice followed standards? Environ Impact Assess Rev 2014; 47: 47-53. doi: 10.1016/j.eiar.2014.03.001

13. Scott-Samuel A. Health impact assessment: an idea whose time has come. BMJ 1996; 313: 183-4. doi: 10.1136/bmj.313.7051.183

14. Harris-Roxas B, Viliani F, Cave B, Divall MJ, Furu P, Harris P, et al. Health impact assessment: the state of the art. Impact Assessment and Project Appraisal 2012; 30: 43-52. doi: 10.1080/14615517.2012.666035

15. Erlanger TE, Krieger GR, Singer BH, Utzinger J. The 6/94 gap in health impact assessment. Environ Impact Assess Rev 2008; 28: 349-58. doi: 10.1016/j.eiar.2007.07.003

16. Dora C. A perspective on health impact assessment, global health, and the role of WHO. In: Kemm J, editor. Past achievement, current understanding and future progress in health impact assessment. Oxford: Oxford University Press; 2012. p. 285-93.

17. Winkler MS, Krieger GR, Divall MJ, Cissé G, Wielga M, Singer $\mathrm{BH}$, et al. Untapped potential of health impact assessment. Bull World Health Organ 2013; 91: 298-305. doi: 10.2471/ blt.12.112318

18. Parry JM, Kemm JR. Criteria for use in the evaluation of health impact assessments. Public Health 2005; 119: 1122-9. doi: 10.1016/j.puhe.2005.05.002

19. Winkler MS. Health impact assessment in complex ecoepidemiological settings in the humid tropics [PhD thesis]. Basel: Swiss Tropical and Public Health Institute, an associated institute of the University of Basel; 2011. 